Volumen: 22

Año: 2020

Numero: 2
Fecha de recibido: $28 / 5 / 2020$

Fecha de aceptado: $7 / 7 / 2020$

Número de Páginas: 73-102
Fecha de publicación: Julio-Diciembre de 2020

Correo: revista.societas@up.ac.pa

URL:https://revistas.up.ac.pa/index.php/societas

\title{
El rol de la educación en la formación de cultura de paz
}

\author{
Role of education in the formation of a culture of peace \\ Luz Marina Bayona Moreno ${ }^{1}$ \\ luz.bayona@uptc.edu.co \\ Luz Stella Ahumada Méndez ${ }^{2}$ \\ luzstellaahumada@gmail.com
}

\begin{abstract}
Universidad Metropolitana de Educación Ciencia y Tecnología. Facultad de Educación.
\end{abstract} Doctorado en Ciencias de la Educación. Panamá, Panamá.

\section{Resumen}

El presente artículo de revisión analiza el papel de la educación en la construcción de cultura de paz, desde las concepciones teóricas y el ejercicio de las competencias ciudadanas y emocionales, para implementar dicha cultura en el ámbito escolar; con una metodología desarrollada por medio del enfoque hermenéutico y una revisión bibliográfica a 50 fuentes documentales entre libros y artículos, interpretados a partir de un fichaje, para su análisis y conclusiones. Resultados, el constructo teórico de cultura de paz reconoce en la educación su papel trasformador y camino acertado para construir tejido social, por medio de la implementación de competencias ciudadanas y emocionales, tendientes a generar procesos de socialización y convivencia entre los estudiantes. Conclusión, la educación como eje transformador de la cultura

${ }^{1}$ Estudiante de Doctorado en Ciencias de la Educación con énfasis en Investigación, Evaluación y Formulación de Proyectos Educativos en la Universidad Metropolitana de Educación, Ciencia y Tecnología - UMECIT. Magister en Historia de la Universidad Pedagógica y Tecnológica de Colombia- Especialista en Pedagogía de los Derechos humanos la Universidad Pedagógica y Tecnológica de Colombia Email: luz.bayona@uptc.edu.co

${ }^{2}$ Doctora en Educación Social de la Universidad de Granada, Magíster en Educación, de la Universidad Pedagógica Nacional. Docente Doctorado del programa de Educación de la Universidad UMECIT. E-mail: luzstellaahumada@gmail.com 
de paz, a través de la promoción en derechos humanos, genera procesos de socialización y convivencia, orientados a través del ejercicio de competencias ciudadanas y emocionales.

\section{Palabras clave: Cultura de paz, competencias ciudadanas competencias emocionales}

\section{Abstract}

This review article analyzes the role of education in the construction of a culture of peace, from theoretical conceptions and the exercise of civic and emotional competences, to implement said culture in the school environment; with a methodology developed through the hermeneutical approach and a bibliographic review of 50 documentary sources between books and articles, interpreted from a check-in, for analysis and conclusions. Results, the theoretical construct of a culture of peace recognizes in education its transformative role and the right path to build social fabric, through the implementation of civic and emotional competencies, tending to generate processes of socialization and coexistence among students. Conclusion, education as a transforming axis of the culture of peace, through the promotion of human rights, generates processes of socialization and coexistence, oriented through the exercise of civic and emotional competencies.

Keywords: Culture of peace, civic competencies, emotional competencies

\section{Introducción}

Este artículo de revisión resultado de una investigación sobre el tema, analiza el papel de la educación en la construcción de una cultura de paz, a partir de las concepciones teóricas y acciones a desarrollar por medio del ejercicio de las competencias ciudadanas, emocionales y socioemocionales, para implementar la cultura de paz en el ámbito escolar; por consiguiente, realiza un acercamiento teórico a la cultura de paz, así como a las competencias ciudadanas, emocionales y socioemocionales y establece las acciones a desarrollar desde el aula para implementar la cultura de paz en las instituciones educativas.

La educación es por excelencia el mecanismo de transformación social y el medio más apropiado para construir cultura de paz en todos los contextos geográficos, compromete a diversos sectores de la población, que desde su quehacer tienen la responsabilidad social de velar por el respeto a la vida y la erradicación de la violencia, promoción de los derechos humanos y libertades fundamentales; por consiguiente, las acciones que desde la educación permiten el establecimiento de una cultura de paz, implican formar para la paz desde las aulas por medio del ejercicio de 
competencias ciudadanas como la convivencia, la participación democrática, el respeto a las leyes y normas que orientan la vida en comunidad, los derechos fundamentales y el reconocimiento a la diferencia, pluralidad y diversidad humana; en razón a que las competencias ciudadanas como conocimientos y habilidades, permiten que las personas contribuyan a la construcción de una sociedad democrática, bajo el reconocimiento de sus derechos fundamentales y la capacidad para adaptar medidas de resolución pacífica de conflictos y sana convivencia.

Por su parte, las competencias emocionales desarrollan habilidades y uso de la razón para reconocer emociones o sentimientos, expresarlos de forma adecuada, conocerse a sí mismo, identificar manifestaciones emotivas en los demás, adaptarse a los diferentes entornos sociales y generar ambientes de sana convivencia; pues hoy más que nunca, las nuevas tendencias mundiales están demandando de la educación competencias que fortalezcan la capacidad emocional del ser humano, e influyan en la interacción personal, para hacer frente a las adversidades del día a día, mediante el ejercicio de acciones favorables frente a los cambios repentinos de la sociedad.

\section{Cultura de paz}

La cultura de paz emerge en el año 1945, cuando finaliza la segunda guerra mundial y surgen organizaciones de carácter internacional como la ONU y la UNESCO, destinadas a preservar la paz por medio de la cooperación a través de la educación, la ciencia y la cultura entre los países a nivel mundial; a través de la historia, la ausencia de cultura de paz ha dejado a su paso millones de víctimas y violaciones de derechos humanos.

El propósito de la ONU ha sido mantener la paz y la seguridad internacional, tomando medidas preventivas para evitar actos de agresión con el fin de "lograr por medios pacíficos, y de conformidad con los principios de la justicia y del derecho internacional, el ajuste o arreglo de controversias o situaciones internacionales susceptibles de conducir a quebrantamientos de la paz" (Calduch,1991, p.3).De hecho, con la creación de la ONU nacen iniciativas por parte de los países involucrados en conflictos bélicos, para prevenir actos de violencia entre las naciones y garantizar la seguridad de los Estados, bajo criterios de justicia en la solución pacífica de conflictos cuando existan amenazas a la paz en el campo internacional, a fin de preservar el respeto y defensa de los derechos humanos dentro de la población mundial y evitar que actos de barbarie vuelvan a replicarse, ante cifras tan alarmantes si se tiene en cuenta que "las dos guerras mundiales costaron la vida de más de 100 millones de personas y que la humanidad adquirió, con la bomba atómica, la capacidad de auto aniquilarse" ( Portugal Mendoza,2009,p.39). 
Así mismo, la UNESCO busca establecer la paz en la cotidianidad de las personas, mediante acciones conjuntas de la educación, la ciencia y la cultura a nivel mundial, por medio de acciones tendientes a instaurar una cultura de paz, que "supone la construcción de un marco de vida de acuerdo con la noción de dignidad humana, en el que todos los excluidos, los aislados y los marginados encontrarían la posibilidad de una verdadera reinserción social" (Monclús y Saban,1996, p.138).Por consiguiente, el proyecto de cultura de paz de la UNESCO, traspasa las fronteras que lo relacionan solamente con la ausencia de guerra, es una cultura para construir tejido social, erradicando por completo todas aquellas acciones generadoras de violencia, a partir de la desigualdad social, la injusticia, la discriminación, el racismo, la intolerancia, la falta de oportunidades de acceso a la educación y condiciones de vida digna para todos, ante lo cual, es preciso replantear acciones dentro del marco de la democracia, la solidaridad, el respeto por la diferencia, la diversidad étnica y multicultural de los pueblos.

Ahora bien, un acercamiento teórico al concepto cultura de paz, permite inferir que no existe un concepto único o universal de cultura de paz, Tünnermann (1906) sostiene que cultura de paz, es un concepto en gestación que se enriquece diariamente con nuevos aportes, con la solución pacífica de los conflictos, tolerancia, mediante la puesta en escena de procesos de concertación y reconciliación. En efecto, la cultura de paz implica un esfuerzo conjunto de la sociedad para modificar esquemas de pensamiento y prácticas que obstaculizan la paz, "es hacer que los niños y los adultos comprendan y respeten valores universales, como la justicia, la libertad, la democracia, los derechos humanos, la igualdad, la tolerancia, la cooperación y la solidaridad" (Cabello, Carmona, Gorjón, Iglesias, Sáenz y Vázquez ,2016, p.26). En otras palabras, la cultura de paz se logra por medio de valores, actitudes y comportamientos, dentro de los cuales prevalezca la solución pacífica de los conflictos, el respeto por la diferencia y pleno ejercicio de la democracia, donde las personas tengan posibilidad de participación en los procesos del desarrollo de sus comunidades, para reducir los niveles de pobreza, desigualdad y discriminación.

\section{Cultura de paz y educación}

La educación es por excelencia el mecanismo de transformación social y el medio más apropiado para construir cultura de paz en todos los contextos geográficos, compromete a diversos sectores de la población, que desde su quehacer tienen la responsabilidad social de velar por el respeto a la vida y la erradicación de la violencia por medio del diálogo, en búsqueda del respeto 
y promoción de los derechos humanos y libertades fundamentales; bajo este criterio la cultura de paz "nace de reconocer el derecho que tienen todas las personas a gozar de una vida pacífica, digna y justa; se realiza a través del diálogo y la cooperación, requiere el consenso sobre unos cuantos valores mínimos compartidos" (Pérez Viramontes, 2018, p. 30). Es decir, la educación como eje transformador para el cambio cultural y progreso social favorece la formación integral del ser humano, lo sensibiliza ante las problemáticas sociales y lo motiva hacia la búsqueda de las soluciones pertinentes para afrontar la realidad. Tal como lo expresan Hinojosa García y Vázquez Gutiérrez (2018) Para iniciar el cambio de paradigmas hacia una cultura de paz, la herramienta y plataforma es la educación, para evidenciar como la violencia ha permeado la cultura, como consecuencia de la falta de información, conocimiento y reflexión, pues la violencia se sostiene en la ignorancia. Por lo tanto, la educación es la oportunidad para desmitificar violencia, en cuanto ofrece herramientas de cambio para transmitir cultura y buenas prácticas de interacción con los demás, de respeto en la diversidad, así como estrategias de diálogo y concertación ante las diferencias.

Ahora bien, las organizaciones internacionales destacan el papel transformador de la educación en el establecimiento de la cultura paz "Reconociendo también la función que desempeña la educación en lo que respecta a forjar una cultura de paz y no violencia, en particular mediante la enseñanza de la paz y la no violencia a los niños" (ONU,1998, p.2). Por consiguiente, se reconoce en la educación el camino para edificar la cultura de paz, a través de la formación de valores, tendientes a generar procesos de socialización y convivencia entre los estudiantes, pues la escuela como escenario social por excelencia no ha sido ajena a los conflictos, en ella convergen la diversidad y multiculturalidad y es allí donde a través de la formación se deben gestionar estrategias que permitan dirimir los conflictos de forma pacífica, mediante una actitud crítica y cambio de mentalidad ante las acciones violentas, y en este sentido "acabar con la idea de que las guerras y las violencias son normales e inevitables, y que son la única alternativa ante los conflictos, es importante el papel de la educación, que es un instrumento de transformación pacífica" (Bahajin,2018, p.2).

Con base en lo anterior, corresponde a la educación actuar ante la normalización que se hace de la violencia, creando conciencia social y rechazo colectivo frente a las acciones que atentan contra la libertad, la justicia y la vida del ser humano, para eliminar impunidad como práctica cotidiana, ante hechos que degradan la dignidad del ser humano. En efecto, las organizaciones 
internacionales vuelven su mirada a la educación para que los gobiernos y la sociedad civil enruten actividades hacia la promoción y el fortalecimiento de una cultura de paz en el nuevo milenio, expresando que "La educación a todos los niveles es uno de los medios fundamentales para edificar una cultura de paz. En ese contexto, es de particular importancia la educación en la esfera de los derechos humanos" (ONU,1999, p.141). Más aún, en la actualidad que la violación a los derechos humanos se da en todos los escenarios sociales y geográficos, la educación en derechos humanos es fundamental para analizar las causas de dicho flagelo y desde pensamiento crítico crear espacios de reflexión sobre actitudes y acciones que atentan contra los mismos en los contextos reales; es decir una educación que permita "entender los Derechos Humanos como inalienables que derivan de la persona, como la práctica en cuanto a defensa y respeto a todos y todas en la vida cotidiana, como el conjunto de normas básicas de convivencia”( Scarfó, 2015, p.33).

Ahora bien, la educación debe generar estrategias para modificar comportamiento y crear acciones preventivas frente a los abusos, la discriminación y el desconocimiento en materia de derechos humanos, pero sobre todo propiciar aprendizajes significativos desde las acciones cotidianas, pues “ Más que una enseñanza teórica la educación para los derechos humanos debe convertirse en una forma de enseñar a adquirir las competencias básicas que se requieren para desenvolverse en la vida respetando los derechos humanos”( Rodríguez Acosta, 2018, p. 4). En otras palabras, prima la educación como mecanismo de cambio para alejar a las nuevas generaciones de los horrores de la violencia, pues las acciones violentas en el mundo han causado grandes daños a niños y jóvenes de forma indiscriminada, afectando su vida y dignidad, lo cual implica repensar la escuela como laboratorio de paz, taller de construcción permanente de respeto y promoción de los derechos humanos, en escenarios de diálogo y concertación, a partir de acciones cotidianas que trasciendan a la familia, para vislumbrar una verdadera transformación en la sociedad "puesto que las guerras nacen en la mente de los hombres, es en la mente de los hombres donde deben erigirse los baluartes de la paz" (ONU, 1999, p.3). Afirmación que pone de manifiesto la necesidad de formar la cultura de paz en el ser, el hacer y el saber, es decir, desde una formación por competencias, tarea propicia para la escuela por cuanto en ella se cultivan las habilidades que tienen los niños para hacer frente a las dificultades que la vida les plantea, teniendo en cuenta que "La educación para la paz ha de ser también una educación para el encuentro, el diálogo, la cooperación, la cesión de confianza y un lugar para desarrollar nuestras potencialidades. Si además entendemos la paz como transformación creativa de conflictos” 
(Labrador,2000, p. 47). Por consiguiente, la formación para la cultura paz implica acciones y uso racional del conocimiento, más aún, cuando los hechos generadores de violencia continúan en aumento, hoy más que nunca se requieren personas competentes para asumir los retos de la sociedad, en razón a las transformaciones sociales, políticas, económicas, culturales y ambientales que necesitan nuevas formas de asumir el conocimiento y ponerlo al servicio de la solución de problemas reales del entorno, como parte de la interacción humana para la construcción del tejido social.

Por otra parte, el drama de la discriminación es otro de los retos para la educación dentro de la formación en cultura de paz, en tanto que propone "eliminar todas las formas de discriminación e intolerancia, incluidas las basadas en la raza, el color, el sexo, el idioma, la religión, la opinión política o de otra índole, el origen nacional, étnico o social" (ONU, 1999, p.138). Acciones que, desde la educación, invitan a erradicar la discriminación en la escuela de hoy, donde perviven la diversidad y la multiculturalidad como consecuencia de las migraciones y desplazamientos forzados de pobladores como campesinos o grupos indígenas a causa de los conflictos sociales, políticos, económicos o religiosos, que aún continúan vigentes. Es en dichos escenarios donde adquiere vigencia la educación para la paz, ya que "El hombre o mujer que tiene poder y control sobre los demás es quien comete actos discriminatorios, con mayor fuerza y frecuencia sobre las personas o grupos débiles, ignorantes en muchos sentidos o vulnerables" (Patiño Alvarado, 2016, p. 118). Ante estas realidades, se debe abordar el tema de la discriminación en el aula, por medio de estrategias de sensibilización en derechos humanos, así como mecanismos e instituciones de defensa y protección de los mismos.

En consecuencia, es pertinente que desde la educación se fomente la cultura de paz a través del conocimiento de la diversidad, reconociendo las diferencias culturales como insumo de aprendizaje en la escuela, donde el currículo evidencie la multiculturalidad de grupos mayoritarios y minoritarios, creando dentro del contexto escolar una simbiosis en la cual las diferentes culturas que conviven, construyen conocimiento a partir de los diversos saberes culturales y se complementen en la diferencia. Situación que implica un cambio estructural en la planeación curricular de contenidos, prácticas educativas y diálogo de saberes, desde cada cultura, que comprometa la acción de directivos, capacitación de docentes y políticas educativas, como forma de crear cultura de paz, para reconocer el aporte cultural de los diversos grupos en la construcción de la sociedad; Dicho en otras palabras, la cultura de paz se evidenciará en la sana convivencia de 
los entornos educativos, a través de prácticas y estrategias donde los estudiantes comprendan que ser diferente no es ser mejor ni peor que el otro, que la diversidad de culturas implica otra cosmovisión, otros mundos posibles, otras costumbres y formas de vida que enriquecen su conocimiento desde el pluralismo cultural y bajo ninguna circunstancia, ser motivo de discriminación o conflicto en la escuela. Lo dicho hasta aquí, deja claro el papel tan importante que tiene la escuela en la construcción de una cultura de paz, Según Alvarado (2016) como lugar privilegiado para enseñar a las nuevas generaciones los principios para vivir en una sociedad orientada a la convivencia pacífica, Por tanto, no se debe desconocer el aporte de los educadores a la paz en cuanto al nivel de contenido y de relación, donde la enseñanza de la paz es más que un contenido de aprendizaje, es un producto de interacción de docente con sus estudiantes.

\section{Educar para la paz desde las aulas}

En palabras de Mayor Zaragoza (2003) la educación para la paz es un proceso de participación que debe desarrollar la capacidad crítica, para los nuevos ciudadanos del mundo, enseñar y aprender soluciones ante los conflictos, la guerra, la violencia, el terrorismo, la explotación de género, el daño ambiental, negándose a todas las acciones que atenten contra la vida y la dignidad humana, mediante comportamientos que permiten una transición de la cultura de guerra a una cultura de paz. Es decir, una educación para la paz, reflejada en un cambio de paradigma frente a la forma de asumir la realidad social, que genere aprendizajes significativos para los estudiantes, a partir de las realidades del contexto, y que genera transformaciones sociales al interior de las instituciones educativas; en razón a que:

La educación para la paz propone acciones para aprender, enseñar y construir colectivamente una sociedad que vea, en los conflictos, oportunidades de transformación que pueden tramitarse de formas diferentes a la armada. Se trata de una educación para la vida, que enseñe a amar, a disentir, a expresar la diferencia, a convivir en ella. (Correal y Fajardo,2015, p. 10)

Se trata de una construcción colectiva de paz, que ve en las dificultades una oportunidad de aprendizaje, sin desconocer que el conflicto seguirá formando parte de la vida misma, implica superar las diferencias a pesar de la adversidad, pues donde haya interacción humana, existirán diferencias que se deben gestionar de forma adecuada, no se trata de eliminar al adversario, es aprender a convivir en la diferencia. Con base en lo anterior, Cerdas Agüero (2015) manifiesta que la educación para la paz constituye un proceso de aprendizaje en el cual el ser humano es agente 
de transformación, prioriza en la persona al creer que las capacidades para participar de forma autónoma, no violenta y activa en el desarrollo humano e incidir en la sociedad para promover y construir la paz. Situación que implica de parte de la educción empoderar al estudiante en cuanto al ejercicio de sus deberes, el conocimiento de sus derechos y practica de valores, para ser protagonista del cambio que la sociedad espera de él, así desde su comportamiento generar de una nueva realidad, con actitudes que impacten de forma positiva los contextos violentos, en pro de una cultura de paz.

Por otra parte, la UNESCO (1995) destaca en el fortalecimiento de una cultura de paz, la participación de las mujeres, en razón a que la cultura de la violencia les ha impuesto desventajas, como madres cabeza de familia, refugiadas, desplazadas, viudas y huérfanas; sin embargo, a pesar de estas dificultades las mujeres han desarrollado conocimientos y competencias para sobrevivir, que se convierten en fortaleza para reconstruir y restaurar la sociedad desde una cultura de paz. Por consiguiente, hoy la sociedad tiene una deuda pendiente de reivindicación con las mujeres, pues a lo largo de la historia su protagonismo se ha invisibilizado y a pesar de los esfuerzos, persiste aún una marcada desigualdad en cuanto a oportunidades de acceso a educación de calidad y en el campo laboral la inequidad es muy notoria en cuanto a oportunidades de trabajo digno; así mismo, cada vez son más altas la cifras de violencia contra la mujer, representadas en feminicidios, abuso sexual, estigmatización y acciones machistas, entre otras que evidencian la urgencia de una cultura de paz que verdaderamente forme resignifique desde la educación el papel de la mujer en la sociedad.

Además, Jacques Delors (1996) sostiene que la misión de la educación es capacitar a todos los individuos y desarrollar todos sus talentos, como también su potencial creativo, sin dejar de lado la responsabilidad de sus propias vidas y la realización de los objetivos particulares de las personas. El autor en mención destaca que la educación debe estructurarse teniendo en cuenta cuatro aprendizajes, que se convierten en los pilares de la apropiación del conocimiento a lo largo de la vida de cada persona, y que, desde luego, son la base de la educación para la paz:

Aprender a conocer se refiere a todas las teorías necesarias para la formación sobre el tema; aprender a hacer, corresponde a aplicar las técnicas e instrumentos en cada uno de los contextos; aprender a vivir juntos es la participación y cooperación con los otros para la consolidación de la paz y aprender a ser, concierne al fortalecimiento de los valores y principios que cada persona debe poseer para su actuación en las diferentes acciones de la vida. 
Ahora bien, en el contexto colombiano, la formación para la paz está reglamentada en la Constitución política de 1991, articulo 22 que establece "La paz es un derecho y un deber de obligatorio cumplimiento" (Constitución política de Colombia,1991). En tal sentido, el Estado y la sociedad colombiana deben velar por que el derecho y debe a la paz se garantice a todos los colombianos en igualdad de condiciones, desde la promoción de los derechos humanos, la diversidad, multiculturalidad y respeto por la diferencia; más aún, cuando el mismo documento constitucional lo promociona desde la educación en el artículo 67. "la educación formará al colombiano en el respeto a los derechos humanos, a la paz y a la democracia" (Constitución política de Colombia,1991). Así, el Estado promueve el derecho a la paz, desde la educación en el contexto de los derechos humanos y la democracia, tarea que implica gran responsabilidad para las instituciones educativas. Igualmente, dentro de los fines de la educación colombiana se plantea "La formación en el respeto a la vida y a los demás derechos humanos, a la paz, a los principios democráticos, de convivencia, pluralismo, justicia, solidaridad y equidad, así como en el ejercicio de la tolerancia y de la libertad" (Ley general de Educación,1994) lo cual ratifica el interés del Estado colombiano, para promover a través de la educación valores tendientes a establecer una cultura de paz, a fin de mantener el orden social.

Adicionalmente a lo anterior, el gobierno nacional con la Ley 1732 del 2014 y el decreto 1038 del 2015, implementó la enseñanza de la cátedra de la paz en las instituciones educativas del país, para encaminar acciones a fin de que los estudiantes adquieran desde su cotidianidad las competencias necesarias para aprender a relacionarse con sus semejantes a partir de la diferencia, el respeto, la tolerancia y la convencía pacífica y lograr que estos comportamientos desdibujen la cultura de la violencia y trasciendan a otros escenarios sociales.

Según Salamanca, Rodríguez, Ovalla, Pulido \& Molano (2016) ante los desafíos del posconflicto, es fundamental el aporte de la educación hacia el tránsito a la paz, que permita reconstruir la sociedad colombiana empezando por los nuevos espacios de convivencia, donde la educación juega un papel importante en la construcción de escenarios de discusión, que inicien del respeto por el otro como un par necesario para la construcción de la cultura de paz. Así, la estrategia desde la educación promueve espacios de concertación, para que los estudiantes conozcan y contextualicen la historia del país, identifiquen las causas y consecuencias de los conflictos, reconozcan los hechos históricos y sus protagonistas; a partir de los mismos se generen escenarios 
de reflexión, para evitar que dichas acciones violentas vuelvan a ser parte de la realidad social del país.

Por otra parte, Jojoa Patiño (2016) indica que la cátedra de la paz que se orienta en el país asume contenidos en relación a los derechos humanos, la paz, valores ciudadanos, principios democráticos, respeto y protección del medio ambiente, inclusión e igualdad, los cuales deben instaurarse en todos los sectores del sociedad y no solo en el educativo, exige una cualificación de los maestros, replanteamiento de la pedagogía tradicional, para desarrollar la capacidad de transformar los conflictos en todo los estamentos de la sociedad. Es decir, una orientación basada en estratégicas didácticas que favorezcan la conexión directa entre el conocimiento teórico y las situaciones reales del contexto, enfocadas a la práctica por ejemplo análisis y propuestas de alternativas de solución ante casos reales y estudios de casos sobre hechos del entorno social, para potencializar en los estudiantes aprendizajes significativos, con sentido crítico que generen conciencia social frente al respeto por la diferencia, defensa de los derechos humanos y casos de abuso y discriminación, entre otras actividades que le den sentido y contexto social a la cátedra de la paz.

Ahora bien, a nivel del manual de convivencia las instituciones educativas la cultura de la paz se configura con la Ley de convivencia escolar implementada para

Fomentar y fortalecer la educación en y para la paz, las competencias ciudadanas, el desarrollo de la identidad, la participación, la responsabilidad democrática, la valoración de las diferencias y el cumplimiento de la ley, para la formación de sujetos activos de derechos. (Ley 1620, 2013, p.8)

Dicho en otras palabras, este mecanismo de normatividad establece, una ruta de navegación para prevenir y denunciar ante las autoridades competentes las conductas afectan la convivencia escolar y el ejercicio de los derechos humanos en el contexto educativo y como instancias que afianza la cultura de paz en las instituciones educativas se debe implementar resignificando el manual de convivencia, documento que hace parte del Proyecto Educativo Institucional (PEI) de la institución educativa, donde se plasman normas y acuerdos que facilitan la convivencia y regulan las actuaciones cotidianas de los integrantes del contexto educativo.

\section{Acciones propuestas desde la educación para formar cultura de paz}

En cuanto a las acciones que se deben asumir desde la educación para promover a la cultura de paz la ONU(1999) recomienda para los niños desde la primera infancia, formación en valores 
y actitudes que les permitan resolver los conflictos pacíficamente en el marco del respeto por la dignidad humana, la tolerancia y no discriminación, igualdad de acceso a la educación para niñas y mujeres, revisión de los planes de estudio y textos escolares teniendo en cuenta la educación para la paz y los derechos humanos; En este sentido, dichas acciones se deben orientar en las instituciones educativas desde el ejercicio de las competencias ciudadanas y la formación en competencias emocionales y socioemocionales.

\section{El ejercicio de las competencias ciudadanas}

Chaux y Ruiz (2005) definen las competencias ciudadanas como un conjunto de capacidades y habilidades cognitivas, emocionales y comunicativas que, articuladas con conocimientos básicos, determinan las actuaciones morales y políticas de los ciudadanos, evidenciadas por medio del ejercicio de la ciudadanía en diferentes contextos. Dicho de otra manera, las competencias ciudadanas se evidencian a través del ejercicio ciudadano de hechos que promueven valores para consolidar la sociedad democrática, son el saber hacer del ciudadano en su contexto social, por medio de la interrelación con los demás; así, la institución educativa debe orientar desde el currículo acciones para que los estudiantes adquieran en la cotidianidad competencias necesarias de interrelación con sus semejantes, a partir de la diferencia, el respeto, la tolerancia y la convencía pacífica, las cuales repercuten en comportamientos que transforman la cultura de la violencia y trasciendan a otros contextos sociales.

Ahora bien, el Ministerio de Educación Nacional (2003) organiza las competencias ciudadanas en tres grupos convivencia y paz, participación y responsabilidad democrática y pluralidad, identidad y valoración de las diferencias. La convivencia y la paz basadas en la consideración de cada persona como ser humano; La participación y la responsabilidad democrática orientada hacia la toma de decisiones en diversos contextos, respetando los derechos fundamentales de los individuos, los acuerdos, las normas, las leyes y la Constitución. La pluralidad, la identidad y la valoración de las diferencias desde el reconocimiento de la diversidad humana y los derechos de los demás. En este sentido las competencias ciudadanas responden a los retos de la actualidad, cuando los cambios educativos plantean el paso de una educación basada en la adquisición de conocimientos teóricos, a una educación orientada desde desarrollo de competencias, pues los problemas que afectan actualmente a la población estudiantil obedecen a 
dificultades sociales no percibidas por la educación que se imparte en las instituciones educativas; dificultades que son detonantes de conflictos sociales.

Es decir, las competencias ciudadanas deben formar individuos en el reconocimiento de sus entornos, su historia, sus problemas, sus necesidades reales y a partir de esas dificultades propongan alternativas de transformación por medio del ejercicio ciudadano, unas competencias ciudadanas que trascienda las barreras de la escuela y formen ciudadanos que "interiorizan y comprenden las dinámicas particulares de su contexto y a partir de ello se sitúan como ciudadanas o ciudadanos, con criterio y poder de decisión, para hacerse participes de la acción y transformación social y garantes del bienestar general” (García y González ,2014, p.375).

Por otra parte, Murillo Castaño y Castañeda Aponte (2007) mencionan que una de las particularidades del modelo de las competencias ciudadanas en Colombia, es la formación ciudadana, buscando superar el enfoque tradicional de abordar los temas desde la visión del docente, bajo el control social, donde las relaciones entre profesores, padres y alumnos son de obediencia, sometimiento y castigo, opuesto a las competencias ciudadanas que se fundamentan en el enfoque de ciudadanía juvenil, que propenden por un desarrollo más democrático, plural y participativo, en las que prima más la cohesión social, la comprensión, el desarrollo de la autonomía y de la capacidad crítica, para que el resultado sea el acatamiento voluntario de la norma. Por lo tanto, la formación de competencias ciudadanas en la escuela implica la transformación de prácticas políticas desde el currículo, con participación e inclusión de todos los integrantes de la comunidad educativa dentro del marco del respeto, la defensa de los derechos humanos y la convivencia pacífica; expresado en un cambio a las estructuras rígidas de poder, que den paso a la participación colectiva, por medio del diálogo, la búsqueda de acuerdos y el reconocimiento de saberes culturales en las comunidades, escuchando las iniciativas y necesidades de los diferentes actores, en búsqueda del bien común frente a la solución de sus realidades; es decir el desarrollo de las competencias ciudadanas permite que los estudiantes "participen activamente no sólo en la institución educativa, sino también en la esfera pública y en las organizaciones a las que se vinculen, para promover intereses colectivos, defender derechos y cumplir deberes como ciudadanos y miembros de una comunidad” (MEN, 2003,p. 8).

Conviene subrayar que, el desarrollo de estas competencias en los entornos educativos, motiva en los estudiantes el asumir una posición acertada frente a los problemas de su entorno, fortalecer las relaciones con los demás, así como valores y actitudes que lo identifican dentro de 
una comunidad educativa y que como parte de ella deben acogerse a las normas y actuar de manera solidaria y respetuosa con sus compañeros, para garantizar desde la escuela la vivencia y el respeto por los derechos humanos. Hay que mencionar además que para Chaux y Ruiz (2005) las competencias ciudadanas modifican la conducta del ciudadano y desarrollan competencias individuales específicas, pero los contextos sociales particulares pueden obstaculizar o permitir el ejercicio de competencias en cada persona; los cambios sociales no dependen solamente de los individuos, los contextos sociales deben ser estudiados y problematizados, promoviendo transformaciones para que los individuos ejerzan sus competencias, desde acciones donde las competencias sean llevadas a la práctica.

Lo planteado hasta aquí, supone una sinergia entre el ciudadano y su entorno social, para que el ejercicio de las competencias ciudadanas modifique comportamientos agresivos que alteran los entornos democráticos, así la educación estimule en los estudiantes el pensamiento crítico, para participar activamente en las decisiones que afectan la vida de sus comunidades con propuestas viables y acciones responsables, frente a las necesidades de los demás y la solución a problemáticas reales del entorno; pues ante las demandas actuales de las sociedad se requiere formar competencias para saber "vivir juntos en una época como la nuestra, caracterizada por el pluralismo de valores y de culturas, el ascenso del individualismo, los desafíos de la globalización y la proliferación de diferentes conflictos que amenazan la cohesión social"'(Tuvilla Rayo,2002, p. 11). En este orden de ideas, se deben configurar acciones para la paz que desdibujen la cultura de la violencia, formando ciudadanos con valores democráticos que respeten los derechos humanos, para atender la realidad del país permeada de acciones violentas en todos los escenarios sociales; ante esta realidad el sistema educativo urge de una formación en competencias ciudadanas que restaure el tejido social, mediante la acción conjunta de estudiantes y maestros; tal y como lo mencionan Chaux \& Ruiz (2005) formar en competencias ciudadanas implica desarrollar la responsabilidad moral entre docentes y estudiantes, construir ambientes educativos desde los proyectos de vida, con acuerdos y acciones que mejoren la interrelación con los demás; establecer relaciones de confianza en el marco de la responsabilidad, el dialogo y la escucha para estar atento, dar razón y justificar puntos de vista, acuerdos y desacuerdos de construcción colectiva con los demás.

En definitiva, las competencias ciudadanas como conocimientos y habilidades, permiten que las personas contribuyan a la construcción de una sociedad democrática, bajo el 
reconocimiento de sus derechos fundamentales y la capacidad para adaptar medidas de resolución pacífica de conflictos y sana convivencia, en la pluralidad y el respeto por la diferencia; pues para el caso colombiano las distintas manifestaciones de violencia en el territorio, han generado afectaciones a la población civil a través de pérdida de vidas humanas, desplazamiento forzado, pobreza, desintegración familiar y desarraigo de sus tierras y centenares de viudas y huérfanos. Como es de esperarse, las instituciones educativas no han sido ajenas a este conflicto que vive el país, por el contrario, han sido escenarios de violencia donde convergen cantidad de factores fruto del conflicto armado como familias desplazadas, grupos migrantes, desintegración familiar, desarraigo y extrema pobreza, que entre otros motivos causan afectaciones a los estudiantes, alteran su proceso de enseñanza-aprendizaje, pues los efectos de la violencia, permean sus vidas y dejan secuelas que se ven reflejadas en las instituciones educativas a través de serios conflictos sociales. Por lo tanto, la formación de competencia ciudanías en las instituciones educativas no puede ser un modelo importado, debe atender las realidades del contexto, intereses y problemáticas reales de los directamente afectados, formando responsabilidad política y social y honestidad para asumir con pulcritud las funciones que implican cargos de administración o elección, así, el futuro funcionario evitará causar daño a su comunidad y se abstendrá de cometer acciones malintencionadas, u optar por decisiones que menoscaben la confianza de sus electores y lo responsabilicen de actuaciones inapropiadas ante la sociedad.

\section{Gestión de las competencias emocionales en la escuela}

Conangla (2005) define las competencias emocionales como capacidades aprendidas por el ser humano basadas en "la inteligencia emocional, el resultado de su acción puede ser un excelente rendimiento en el trabajo y una mejora en la calidad de vida y niveles de felicidad, estas competencias determinan conductas concretas que facilitan nuestra adaptación al entorno” (p. 94). Así, las competencias emocionales están representadas en habilidades y uso de la razón para reconocer emociones o sentimientos, expresarlos de forma adecuada, conocerse a sí mismo, identificar manifestaciones emotivas en los demás, adaptarse a los diferentes entornos sociales y generar ambientes de sana convivencia; manejar las competencias emocionales implica gestionar adecuadamente las emociones, con empatía y asertividad en beneficio de un clima social favorable, que proporcione experiencias gratificantes al entorno social.

Al mismo tiempo, la autora destaca la importancia de las competencias emocionales dentro de la formación del saber ser de la persona, manifiesta que se relacionan entre sí y parten del "el 
conocimiento de uno mismo. Solo a partir del autoconocimiento y la autocomprensión de nosotros mismos seremos capaces de dar nombre y gestionar nuestros fenómenos afectivos y conseguir construir nuestra compresión de las otras personas y del mundo" (Conangla, 2005, p.94). Adicionalmente, el conocimiento de sí mismo permite identificar sentimientos, tomar conciencia de los estados de ánimo, controlar las reacciones ante diversos episodios de índole emocional y detectar rasgos en la personalidad, para comprender los sentimientos y reacciones diversas ante determinadas situaciones de carácter emocional en los demás.

Ahora bien, Calderón, González, Salazar \& Washburn (2010) sostienen que la formación emocional juega un papel primordial en la vida de las personas, especialmente "en las niñas y niños, ya que concibe a éstas y éstos desde un punto de vista holístico y preventivo, siempre en mira a estilos de vida mejores y a las relaciones intrapersonales e interpersonales más saludables" (p.11). De este modo, la formación en competencias emocionales pretende desde la escuela suministrar herramientas necesarias, para que los estudiantes identifiquen y gestionen sus emociones y las de los demás y al mismo tiempo comprendan la naturaleza emocional del ser humano; dicha formación emocional hará comprender al estudiante, que las emociones se sienten de forma individual y permiten a cada persona actuar diferente ante las mismas situaciones, pues no todas las personas reaccionan igual frente al mismo hecho, ni expresan los sentimientos de forma similar. Por su parte Bisquerra \& Pérez (2007) afirman que las competencias emocionales son "el conjunto de conocimientos, capacidades, habilidades y actitudes necesarias para comprender, expresar y regular de forma apropiada los fenómenos emocionales" (p.69). Es decir que las competencias emocionales se identifican con la disposición personal, para manifestar emociones de forma espontánea y relacionarse asertivamente con los demás. En este orden de ideas, las competencias emocionales son importantes para el desarrollo personal y social, ya que implican manejo adecuado del comportamiento, ante determinadas situaciones cotidianas, evidenciadas a través de cualidades necesarias para ejecutar actividades que requieren permanente interrelación con los demás.

\section{Clasificación de las competencias emocionales}

Bisquerra \& Pérez (2007) clasifican las competencias emocionales en: Conciencia emocional, regulación emocional, autonomía personal, inteligencia interpersonal y habilidades de vida y bienestar. 
Conciencia emocional. Villanueva, Prado, González \& Montoya (2014) afirman que "la conciencia emocional incluye también aspectos actitudinales, tales como la forma en que las experiencias y expresiones emocionales son detectadas en uno mismo y en los demás" (p.772). De hecho, la conciencia emocional implica habilidad para reconocer en sí mismo sentimientos, emociones, estados temperamentales e impulsos que pueden afectar el entorno emocional en determinado contexto social, permite que la persona tome decisiones correctas y asuma acciones pertinentes que contribuyan a la solución de un problema o conflicto social, en el cual está inmerso el individuo; la conciencia emocional, permite identificar estados de ánimo en las personas, entender cambios en su comportamiento, ejercer control y dominio de las emociones que afectan la vida personal o social, detectar actitudes para establecer causas y asumir medidas preventivas ante determinadas situaciones emocionales, que pueden trastornar la convivencia en diferentes entornos.

Regulación emocional. Silva (2005) asume la regulación emocional como un proceso de interiorización, mediante el cual el individuo modifica la intensidad y duración de las emociones, adaptándose a las necesidades de contexto, para alcanzar metas personales y sociales. En otras palabras, es la habilidad para comprender los sentimientos, con el fin de modificar el comportamiento individual e influir en otras personas, para transformar actitudes que afectan la convivencia social.

Autonomía emocional. Fernández Rodríguez (2013) propone la autonomía emocional como un estado afectivo caracterizado por la capacidad de sentir, pensar, tomar decisiones por sí mismo y asumir con responsabilidad las consecuencias de sus actos, que implica para el individuo gestionar sus emociones y sentirse seguro de sus decisiones. De hecho, la autonomía emocional otorga poder a la persona para decidir por sí misma, que episodios le afectan y cuales le son indiferentes, asumiendo el control de su estado de ánimo y enfrentando con madurez situaciones adversar que se le presentan en la vida. Así, la autonomía emocional implica, capacidad para pensar y tomar decisiones por sí mismo, asumir con responsabilidad las consecuencias de los actos, según el libre albedrio; pues el ser humano es el único responsable de su estado de ánimo y de sus emociones; en tal sentido, decide autónomamente sobre sus sentimientos, elije como y hasta qué punto le afectan las situaciones negativas y qué conducta asumir ante determinadas situaciones.

Inteligencia interpersonal. Siberman y Halsburg (2000) afirman que la inteligencia interpersonal es polifacética, no se limita solamente a las habilidades políticas o cualidades 
sociales, incluye ocho habilidades interpersonales tales como: comprender a los demás, expresar sus ideas con claridad, establecer sus necesidades, intercambiar información, influir en otros, resolver conflictos, trabajo en equipo y cambiar de rumbo, las cuales permiten establecer relaciones fuertes y solidas con los que nos rodean. Por lo tanto, cultivar la inteligencia interpersonal, facilita la adaptación al entorno, permite un acercamiento al estado anímico de los demás por medio de una lectura acertada de sus intenciones, para interactuar acertadamente y predecir aspectos de su comportamiento ante eventuales episodios emocionales.

Competencias para la vida y el bienestar. Sánchez García (2017) afirma que las competencias para la vida y el bienestar tienen que ver con la capacidad de adoptar comportamientos apropiados y decisiones acertadas con el fin de enfrentar los desafíos diarios de la vida, permiten organizar la vida de forma sana y equilibrada, generando experiencias gratificantes para obtener bienestar emocional y transmitirlo a los demás. En efecto, las competencias para la vida y el bienestar se relacionan con actitudes de asumir conductas y acciones responsables frente a la solución de problemas, en procura del bienestar personal y social, por medio de las habilidades sociales que se puedan ejercer en determinadas situaciones y contextos particulares; representan equilibrio entre la salud mental y física para proporcionar tranquilidad y armonía al entorno social de cual hace parte el individuo, e implican comunicación asertiva y relaciones de empatía con las demás personas.

\section{La educación emocional en las instituciones educativas}

Sánchez Ramírez (2015) afirma que la educación emocional "Podría considerarse como el proceso educativo tendiente al logro de una personalidad rica y equilibrada que posibilite la participación, activa y efectiva, en la sociedad" (p.20). En consecuencia la educación emocional como proceso formativo, se basa en el fortalecimiento de las competencias emocionales para potencializar desarrollo integral de la personalidad del estudiante, preparándolo para que asuma con madurez emocional los retos que la vida le impone, en beneficio del bienestar individual y social; en razón a que dentro del contexto escolar conviven variedad de conflictos y necesidades sociales que tiene un trasfondo emocional y no es posible su abordaje desde lo académico.

Así, el objetivo de la educación emocional consiste en fortalecer la personalidad y autoestima de estudiantes, para prevenirlo ante situaciones de vulnerabilidad presentes en el contexto escolar, en aspectos como la violencia, el bullying, consumo de drogas, comportamientos agresivos depresión, situaciones de estrés y hasta el suicidio, esta formación emocional permitirá 
un acercamiento a sus propias emociones, para auto reconocerse, identificar sus emociones y las de los demás. Vivas García (2002) resalta la importancia de la educación emocional por cuanto la sociedad del momento, produce tensiones emocionales por el estrés del trabajo, el hacinamiento en las grandes ciudades, los conflictos familiares, la violencia y la marginalidad social, ocasionando vulnerabilidad emocional a las personas, dicha situación reclama del sistema educativo cohesión social, solidaridad y justicia social.

Formación emocional que reclama especial atención en la escuela de hoy, donde el niño afronta una difícil carga emocional a causa del desplazamiento por el conflicto armado, violencia intrafamiliar, pobreza extrema, desintegración familiar y migraciones, los cuales han sido detonantes de problemas que afectan el clima escolar, tales como desmotivación por el estudio, violencia escolar, bajo rendimiento académico, deserción estudiantil y acoso escolar entre otros; razón por la cual más que una formación académica, hoy se deben implementar acciones didácticas desde el aula que promuevan la empatía, la autoestima, manejo adecuado de emociones propias y de los demás; de esta forma la educación emocional contribuye a que el estudiante tome decisiones acertadas respecto a su proyecto de vida.

Igualmente, Sánchez (2010) ratifica la pertinencia de la formación en competencias emocionales, por cuanto estas competencias fortalecen la madurez psicológica y social del estudiante, estimula su capacidad para dar respuestas adecuadas a los problemas cotidianos, evidenciadas en sanas relaciones de equilibrio emocional y rendimiento escolar, autoestima, autoconcepto y responsabilidad. En este sentido, la función de la escuela de hoy es ofrecer en igualdad de condiciones formación académica y en competencias emocionales como parte del desarrollo y formación integral del individuo, desarticulando en este sentido la idea de medir el éxito personal de los estudiantes, sólo desde indicadores cuantitativos de índole académico, pues con los avances de la tecnologías de la información y las comunicaciones en este mundo globalizado es fácil acceder al conocimiento, pero la formación emocional requiere de interacción del estudiante con sus pares, acompañamiento y permanente en la escuela.

Por su parte Bisguerra (2003) reafirma la importancia de la formación en competencias emocionales en razón a los índices elevados de fracaso escolar, dificultades de aprendizaje, estrés ante los exámenes, abandonos en los estudios universitarios, hechos provocan estados emocionales negativos, apatía o depresión y hasta el suicidio, relacionado con deficiencias en el equilibrio emocional que reclaman una atención por parte del sistema educativo. Lo anterior, en razón a que 
las dinámicas sociales y económicas de hoy los jóvenes están muy solos y desorientados emocionalmente, expresan esa carencia afectiva con desinterés por el estudio y manifestaciones violentas que alteran la convivencia en los entornos escolares; la escuela no está atendiendo a esta necesidad sentida que demanda este sector de la población, para conocer sus emociones, responder asertivamente al porqué de dichos actuaciones y comportamientos o cómo afrontar ciertos estados de ánimo propios y de sus compañeros; son situaciones cotidianas que requieren de una formación dentro del contexto de las competencias emocionales al interior de las instituciones educativas.

\section{El papel del docente en la educación emocional}

El docente es agente activo en el desarrollo afectivo y emocional de los estudiantes, para que el alumno desarrolle las competencias emocionales necesita de un docente que administre adecuadamente sus emociones. Fernández-Berrocal \& Extremera (2010) resaltan el papel del docente en la educación emocional, pues el alumno pasa en las aulas gran parte de su infancia y adolescencia, época en que se produce el desarrollo emocional, de forma que el entorno escolar se configura como un espacio privilegiado de socialización emocional y el profesor se convierte en referente importante en cuanto actitudes, comportamientos, emociones y sentimientos. Ante este escenario, el docente se convierte en ejemplo inmediato a seguir por sus estudiantes, en sus manos está la labor de enseñarles a percibir el mundo desde las emociones, mediante acciones didácticas que engloben aprendizajes para solucionar los conflictos pacíficamente, ser tolerantes y respetar

la diferencia y la diversidad, establecer y cumplir pactos o acuerdos, entre otras acciones que solo se aprenden en la interacción diaria con los demás. Igualmente García Retana (2012) afirma que el proceso de enseñanza-aprendizaje está determinado por el manejo que el docente hace de sus emociones o sentimientos y su concepción del acto educativo; es decir, las actitudes del docente contribuyen o dificultan el aprendizaje, en razón a que la educación es un proceso integral, compuesto por conocimientos y emoción que constituyen un todo dialéctico, donde la modificación de uno influye en el otro, en ocasiones el aprendizaje depende más de la emoción, que dé la razón con que se trabajan los contenidos, es decir, si se logra la suficiente motivación emocional, es más fácil llegar a los aprendizajes deseados.

\section{Inteligencia emocional}

Fernández Berrocal \& Ramos Diaz (2004) asocian la inteligencia emocional con fuente de salud y felicidad, en razón al aumento de personas que sufren de estrés, ansiedad o trastornos de salud mental, relacionados con la capacidad para afrontar inteligentemente situaciones 
emocionales cotidianas; ante lo cual los autores proponen fomentar la inteligencia emocional en la familia y el entorno laboral, siendo conscientes que la inteligencia emocional no evitará que los episodios emocionales sucedan, pero afrontarlos con inteligencia emocional disminuirá el desgaste psicológico causal de deterioro de la salud física y mental. Por tal razón, la inteligencia emocional se debe fomentar desde la escuela para facilitar la adaptación social al grupo, logros académicos, sana convivencia e incremento de la autoestima en los estudiantes, como factores que contribuyen a un ambiente escolar adecuado para el desarrollo integral de los educandos y un clima escolar favorable para toda la comunidad educativa.

Por su parte Bradberry \& Greaves (2012) afirman en sus estudios sobre inteligencia emocional que dos de cada tres personas controlan sus emociones, pero no las saben gestionar, identificar ni utilizar en su beneficio, debido a que el colegio enfoca su educción en lo académico e invisibiliza la formación emocional y a su vez, esta inteligencia es más difícil de medir o comprobar en el currículo. En este sentido, la inteligencia emocional, evidencia que determinar el rendimiento de un estudiante solamente desde el aspecto cognitivo, refleja una visión sesgada de su formación por cuanto las capacidades y habilidades para tener éxito en la vida van más allá de las actuaciones intelectuales; muestra de lo anterior son las investigaciones sobre inteligencia emocional que fijan su atención en el aspecto emotivo del estudiante como parte de su formación integral y garantía de bienestar personal y social en los diferentes escenarios.

Igualmente, las emociones como parte inherente del ser humano, repercuten significativamente en varios aspectos a lo largo de su existencia, cada persona asume su carga emocional de forma distinta, según sus expectativas y experiencias de vida, en este sentido, resulta un criterio de importancia a considerar en el aspecto formativo de los estudiantes en la actualidad.

Con base en lo anterior, la escuela debe formar estudiantes que se conozcan así mismos, expresen sus emociones y reaccionen asertivamente ante las dificultades cotidianas, donde más que conocimientos teóricos, se requiere actuar emocionalmente inteligente para superar las adversidades de la vida, entendiendo que el ser humano por naturaleza es emotivo y actúa consciente e inconscientemente de forma emocional, en los escenarios donde la naturaleza lo pone a prueba y las decisiones que tome en determinados momentos, serán trascendentales y afectarán significativamente el transcurso de su vida.

Para Punset (2009) comprender y entender las propias emociones y las de otros, llenan de sentido la vida, generan satisfacción personal y buena interacción con los demás irradiando paz, 
armonía y bienestar en diversas situaciones; pero este estado de armonía social e individual no se manifiesta de forma natural entre las personas, requiere además de buenas intenciones y deseos individuales, el concurso y compromiso de todos los integrantes en los distintos escenarios sociales, por medio del control de emociones negativas y promoción de emociones positivas. Significa que las relaciones humanas, están condicionadas por el estado emocional de las personas, dependen del control de pensamientos para encausar los desafíos de la vida, en beneficio del propio bienestar y relación con los demás, asumiendo conscientemente los estados de ánimo, sentimientos, debilidades y fortalezas a nivel personal y en su interacción con los demás, para la autora "Cada persona encierra dentro de sí un amasijo de sentimientos y emociones tras los recuerdos y las memorias, los fracasos, las pérdidas o la alegría vivida. Como el respirar o el dormir, sentimos y nos emocionamos de forma instintiva" (Punset, 2009, p.16). En consecuencia todas las personas llevan consigo una carga emocional distinta, determinada por acontecimientos del pasado pero, del nivel de formación emocional depende su bienestar social, interacción con los demás y direccionamiento acertado de su proyecto de vida; pues las emociones como radiografías internas del ser humano, aportan información útil, para el autoconocimiento personal y formas de actuar ante diversas situaciones, en búsqueda de la propia felicidad y relaciones de armonía con los demás.

Para Punset (2009) las emociones tanto positivas como negativas, permiten la sobrevivencia en diferentes entornos, las negativas sirven de escudo contra las amenazas y permiten afrontarlas, por ejemplo el miedo previene ante el peligro, la tristeza es la manifestación ante una perdida, es decir, las emociones negativas cumplen una función positiva en la vida, hay que descifrarlas para que actúen a favor, las emociones positivas como la alegría, la tranquilidad o la serenidad, amplían el espectro social y son insumo para enfrentar la adversidad y establecer interrelaciones con los semejantes. En ese orden de ideas, el ser humano en el trascurso de su vida, experimenta emociones positivas y negativas, debe equilibrarlas en beneficio propio, y corresponde a la escuela formar emocionalmente al estudiante, para que aprenda a manejar las adversidades cotidianas y responda asertivamente ante los retos y dificultades de la vida; igualmente, dicha formación emocional dejará claro en el estudiante, que las decisiones que asuma están permeadas de emociones, su adecuado manejo representa cambios positivos de actitudes de comportamiento social, fruto de una acertada formación emocional.

\section{Naturaleza de la inteligencia emocional}


Goleman (1996) ratifica que la inteligencia académica es independiente de la inteligencia emocional, inclusive las personas más brillantes y con un coeficiente intelectual muy alto pueden presentar dificultades al direccionar su proyecto de vida y gestionar sus emociones en favor de sí mismas, para tener una vida plena y gratificante. por consiguiente la educación debe ser un proceso de formación integral, donde confluyan todos los factores en beneficio de individuos que aporten a la sociedad, no solamente desde su conocimiento intelectual, también con una actitud saludable emocionalmente a la construcción de un mundo más humano, que no estigmatice ni censure a quienes están por debajo de los estándares cognitivos que impone la sociedad; en escenarios escolares que desde la formación emocional proyecten personas más felices, antes que cognitivamente cualificadas y con grandes vacíos emocionales en el momento de afrontar los problemas y retos, que la cotidianidad les pone a prueba.

Goleman (1996) destaca en la inteligencia emocional unas características representadas a través de la capacidad de motivarnos a nosotros mismos, de perseverar en el empeño a pesar de las frustraciones, controlar los impulsos, diferir las gratificaciones, regular los estados de ánimo y empatizar y confiar en los demás. Características, que potencializadas debidamente desde la educación contribuyen a formar una sociedad que comprende sus emociones y las de sus semejantes, pues el hombre necesita educar sus emociones para convivir en armonía con los demás, esta formación emocional en conjunto con la formación intelectual, reflejará seres humanos inteligentemente emocionales y preparados para afrontar las realidades del contexto.

\section{Importancia de educar en inteligencia emocional}

Goleman (1996) describe la realidad de esta época, en escenarios familiares, donde ambos padres deben trabajar, los niños quedan abandonados al cuidado del televisor, crecen en condiciones de pobreza, cada vez hay más familias con un solo responsable, los jóvenes no reciben atención cotidiana, hechos que entre otros, menoscaban la salud emocional de niños y jóvenes, ante lo cual el autor se plantea interrogantes en torno a ¿Qué hacer? cuando la familia ya no cumple con su función de preparar a los hijos para la vida; plantea ante dicha dificultad, alternativas de formación para casos como agresividad, indisciplina, depresión, trastornos alimenticios, alcohol y drogas entre otros.

La situación anteriormente descrita, no es lejana a nuestra realidad, pues las instituciones educativas han sido escenarios de violencia, donde convergen cantidad de factores generadores de la misma como son: familias desplazados, grupos migrantes, desintegración familiar, desarraigo 
y extrema pobreza entre otros, que causan afectaciones de tipo emocional al estudiante e impactan su proceso de enseñanza-aprendizaje; en razón a que permean sus vidas y dejan secuelas que se reflejan en la escuela, por medio de conflictos sociales, caracterizados por consumo de drogas, comportamientos violentos, delincuencia, baja autoestima, depresión, suicidio, feminicidio, bajo rendimiento académico y deserción escolar por mencionar algunos; hechos que requieren de la educación una atención especial para sus estudiantes, en cuanto constituyen factor importante de prevención de riesgos psicosociales y contribuyen al bienestar emocional en beneficio de una cultura de paz en el ámbito educativo.

Fernández Berrocal \& Ramos Diaz (2004) reafirman la importancia de enseñar la inteligencia emocional en la escuela, en razón a que la inteligencia emocional influye en la adaptación social y psicológica de los estudiantes, su bienestar emocional, sus logros académicos y su futuro laboral. los estudiantes con poca inteligencia emocional tienen baja autoestima, depresión, ansiedad y mayo posibilidad de consumo de drogas y para que estas habilidades sean adquiridas por los alumnos, el educador debe pose un mínimo de inteligencia emocional ; razones suficientes, para que desde la educación se otorgue igual importancia tanto a la formación emocional, como a la formación intelectual, dentro del desarrollo integral del estudiante, ya que la escuela es el escenario perfecto para potencializar dichas actitudes emocionales, dadas las interacciones que continuamente se dan entre los estudiantes, además que los niños están en una etapa temprana donde se pueden detectar y prevenir problemas comportamentales que le impiden adaptarse a la sociedad; en este sentido, es importante el adecuado manejo que haga el docente de su parte emocional, para orientar al estudiante hacia el fortalecimiento de su personalidad, en aspectos como el autoestima, la asertividad, la tolerancia al fracaso y las frustraciones entre otros factores emotivos que harán parte de su vida cotidiana, pero si existe una adecuada formación emocional serán más fácil de afrontar, tal como lo menciona Dueñas Buey (2020) En situaciones de embargo emocional, las emociones no se reconocen, la persona se deja llevar por ellas sin razonamiento o pueden ser reconocidas, pero la persona no hace caso de los signos extremos, reaccionando inadecuadamente ante determinadas situaciones.

Es decir, la educación en inteligencia emocional, invita al estudiante a detectar sus emociones, no se trata de reprimirlas o negarlas, significa darles un adecuado manejo, para disminuir los problemas que estás puedan generar, hallar lo positivo en cada situación adversa que se presente, medir las implicaciones de la falta de control emocional y estar dispuesto a asumir con 
responsabilidad las consecuencias de la falta de manejo de sus propias emociones ante determinada situación, en aspectos como la ira, el estrés o la ansiedad entre otros.

Para Flores Martínez (2010) los objetivos que se persigue la inclusión de la Inteligencia Emocional en la escuela, serían detectar casos de bajo desempeño emocional, conocer las emociones y reconocerlas en los demás, clasificar los sentimientos y estados de ánimo, modular la emocionalidad, desarrollar la tolerancia a las frustraciones diarias; prevenir el consumo de drogas y otras conductas de riesgo; desarrollar la resiliencia, tener una actitud positiva ante la vida; prevenir conflictos interpersonales y mejorar la calidad de vida escolar. En otra palabras promover desde la educación acciones que sirvan de antídoto, en la institución educativas donde es usual encontrar niños con excelente desempeño académico, pero que terminan abandonando sus estudios ante la ruptura de relaciones de amistad con sus compañeros, otros son el típico indisciplinado y maltratador de sus compañeros y sin embargo lo eligen como líder y representante del curso o los niños con excelente desempeño académico que son objeto de bullying; así como casos de embarazos o drogadicción motivados por la elección de malas amistades o el suicidio ante ambientes depresivos no detectados en el contexto escolar.

\section{Conclusiones}

La educación es la oportunidad para desmitificar violencia, en cuanto ofrece herramientas de cambio para transmitir cultura y buenas prácticas de interacción con los demás, de respeto en la diversidad, así como estrategias de dialogo y concertación ante las diferencias. En este sentido corresponde a la educación actuar ante la normalización que se hace de la violencia, creando conciencia social y rechazo colectivo frente a las acciones que atentan contra la libertad, la justicia y la vida del ser humano, para eliminar impunidad como práctica cotidiana, ante hechos que degradan la dignidad del ser humano. En efecto, la formación para la cultura paz implica acciones y uso racional del conocimiento, más aún, cuando los hechos generadores de violencia continúan en aumento, hoy más que nunca se requieren personas competentes para asumir los retos de la sociedad, en razón a las transformaciones sociales, políticas, económicas, culturales y ambientales que necesitan nuevas formas de asumir el conocimiento y ponerlo al servicio de la solución de problemas reales del entorno, como parte de la interacción humana para la construcción del tejido social.

Las competencias ciudadanas como conocimientos y habilidades, permiten que las personas contribuyan a la construcción de una sociedad democrática, bajo el reconocimiento de 
sus derechos fundamentales y la capacidad para adaptar medidas de resolución pacífica de conflictos y sana convivencia, en la pluralidad y el respeto por la diferencia.

la formación en competencias emocionales pretende desde la escuela suministrar herramientas necesarias, para que los estudiantes identifiquen y gestionen sus emociones y las de los demás y al mismo tiempo comprendan la naturaleza emocional del ser humano; dicha formación emocional hará comprender al estudiante, que las emociones se sienten de forma individual y permiten a cada persona actuar diferente ante las mismas situaciones, pues no todas las personas reaccionan igual frente al mismo hecho, ni expresan los sentimientos de forma similar; por consiguiente se deben configurar acciones para la paz que desdibujen la cultura de la violencia, formando ciudadanos con valores democráticos que respeten los derechos humanos, para atender la realidad del país permeada de acciones violentas en todos los escenarios sociales; ante esta realidad el sistema educativo urge de una formación en competencias ciudadanas que restaure el tejido social, mediante la acción conjunta de estudiantes y maestros

La escuela debe formar estudiantes que se conozcan así mismos, expresen sus emociones y reaccionen asertivamente ante las dificultades cotidianas, donde más que conocimientos teóricos, se requiere actuar emocionalmente inteligente para superar las adversidades de la vida, entendiendo que el ser humano por naturaleza es emotivo y actúa consciente e inconscientemente de forma emocional, en los escenarios donde la naturaleza lo pone a prueba y las decisiones que tome en determinados momentos, serán trascendentales y afectarán significativamente el transcurso de su vida. En otras palabras la formación emocional que reclama especial atención en la escuela de hoy, donde el niño afronta una difícil carga emocional a causa del desplazamiento por el conflicto armado, violencia intrafamiliar, pobreza extrema, desintegración familiar y migraciones, los cuales han sido detonantes de problemas que afectan el clima escolar, tales como desmotivación por el estudio, violencia escolar, bajo rendimiento académico, deserción estudiantil y acoso escolar entre otras acciones generadoras de violencia que repercuten en la sociedad.

\section{Referencias}

Bahajin, S. (2018). La educación como instrumento d ela cultura de paz. Inovacion Educativa, 18-78, 94-111.

Bradberry, T y Greaves, J. (2012). Inteligencia Emocional 2.0. España: Penguin Random House Grupo Editorial. 
Bisquerra, R y Pérez, N. (2007). Las competencias emocionales. Educación XX,61-82

Cabello Tijerina P, C. V. (2016). Cultura de Paz. México: Grupo Editorial Patria, S.A. de C.V.

Calderón R, M., González , G., Salazar , P., \& Washburn M. (2004). El papel docente ante las emociones de niñas y niños de tercer grado. Actualidades Investigativas en Educación, 14-1, 1-23.

Calduch, R. (1991). Relaciones Internacionales. Madrid: Edit. Ediciones Ciencias Sociales.

Calvo, G. (2003). La escuela y la formación de competencias sociales, un camino para la paz. Educación y educadores,6, 69-90.

Cano, E. (2005). Cómo mejorar las competencias de los docentes: guía para la autoevaluación y el desarrollo de las competencias del profesorado, Barcelona: Graó.

Cerdas Aguero, E. (2015). Desafíos de la educación para la paz hacia la construcción de una cultura de paz. Educare, 19-2,1-12.

Correal, X. y. (2015). Educación para la paz con justicia de genero. Bogotá: Ediciones Antropos Ltda.

Conangla Marín, M. (2005). La inteligencia emocional aplicada a situaciones límite. Barcelona: Editorial Amat.

Congreso de Colombia. (1991). Constitucion política de Colombia. Bogotá: Congreso de Colombia.

Chaux, E \&Ruiz, A. (2005). Formación de competencias ciudadanas. Bogotá: Asociación Colombiana de facultades de Educación.

Delors, Jacques, Educación: (1996) hay un tesoro escondido dentro, UNESCO

Dueñas, Buey, M. (2020). Importancia de la inteligencia emocional: Un nuevo reto para la orientación educativa. Educación XXI,5, 79-95.

Fernández Rodríguez, M. (2013). La autonomía emocional. Revista de Claseshistoria, $377,2-12$.

Fernández-Berrocal, P \& Extremera, N. (2004). Desarrolla tu inteligencia emocional. Barcelona: Kairós. 
Flores Martínez, E. (2010). La inteligencia emocional en la educación primaria. Revista de Educación en Extremadura, 118-122.

García Retana, J. A. (2012). La educación emocional, su importancia en el proceso de aprendizaje . Educacion, 36-1,2-24.

García, O. Y. (2014). Competencias ciudadanas: consideraciones desde el concepto d ela ciudadania. plumilla educativa, 13-1,373-395.

Goleman, D. (1996). Inteligencia Emocional. España: Kairós.

Hinojosa, M. (2018). La familia como elemento mediador entre la cultura de paz y la violencia cultural. Revista justicia, 24-34, 405-455.

Jojoa Patiño, J. (2016). Cátedra de paz: Un compromiso con la educacion en derechos humanos. Nova vetera, 87-98.

Labrador, C. (2000). Educación para la paz y cutura de la paz en documentos internacionales. Contextos Educativos,3, 45-68.

López de Dicasillo, N. (2004). Aproximación y revisión del concepto "competencia social". Revista Española de pedagogía,227, 143-146.

lvarado, K. (2016). Cultura de paz en la escuela: Retos para la formación docente. Revista Latinoamericana de Derechos Humanos, 27-2,239-253.

Mayor Zaragoza, F. (2003). Educación para la paz. Educación XXI,6, 17-24.

Monclus, A. Y. (1996). Anális de la creacion de la UNESCO. Revista Iberoamericana de Educación, 12,137-187.

Montenegro Aldana, I. (2005). Aprendizaje y desarrollo de competencias. Bogota: Ediciones Cargraphics.

Murillo Castaño, G., \& Castañeda Aponte, N. (2007). Competencias ciudadanas y construcción de ciudadanía juvenil. Revista del CLAD Reforma y Democracia,37,1-17.

Ministerio de Educación Nacional. (1994). Ley general de educación. Bogotá: Congreso de la República de Colombia.

Ministerio de Educación Nacional. (2004). Formar para la ciudadania si es posoble. Bogotá: Ministerio de Educacion Nacional.

Ministerio de Educación Nacional. (2013). Ley 1620 . Bogotá: Ministerio de Educacion Nacional. 
Ministerio de Educación Nacional. (2015). Ley 1732. Bogotá: Ministerio de Educacion Nacional.

Navarro, Y., López, M., Climent, J. \& Ruíz, M. (2012). Desarrollo de competencias de gestión de conflictos en la formación universitaria. Revista Iberoamericana de Educación, 60$2,1-11$.

Obaco, E. (2019). Competencias docentes para la solución de conflictos en el ámbito escolar. Educere-investigación Arbitrada, 244-77, 37-46.

Patiño Alvarado, M. (2016). Generar ambientes de paz paz erradicar la discriminación, una perspectiva desde la educacion para la paz y la interculturalidad. Ra Ximhai,12-3, 116127.

Pérez Viramontes, G. (2018). Construir paz y transformar los conflictos. México: Universidad Jesuita de Guadalajara.

Portugal Mendoza, C. (1996). Introducción a la cultura de paz. Lima: Editorial Trama de Rubelionil Ramirez Ramos.

Punset, E. (2009). Brújula para navegantes emocionales. España: Aguilar.

Rodríguez Acosta, V. (2018). Educación para los derechos humanos. Un estudio necesario. Revista de estudios del desarrollo social: Cuba y América Latina, 6-2, 1-8.

Salamanca, M., Rodríguez, M., Cruz, J. D., Ovalle, R., Pulido, M. A., \& Molano, A. (2016). Guía para la implementación de la cátedra de paz. Bogotá, D. C.: Editorial Santillana, Universidad Javeriana

Sánchez García, M. (2017). Orientacion profesional y personal. Madrid: Universida Nacional de Educación a Distancia.

Sanchez Ramirez, A. (2015). La educacion emocional, directrices para el desarrollo de programas de inteligeci aemocional en centros de educacion primaria. Madrid: Publicaciones unirioja.

Sánchez, J. (2010). La competencia emocional en la escuela: una propuesta de organización dimensional y criterial. ensayos. Revista de la Facultad de Educación de Albacete, 25,79-96.

Scarfó, F. (2015). Educación en Derechos Humanos y la educación terciaria: una necesidad mutua y multiplicadora. Reencuentro, 70, 25-46. 
Silberman, M. \&. Halsburg, F. (2000). Inteligencia Inerpersonal, una nueva manera de relacionarse con los demás. Barcelona: paidos.

Silva, J. (2005). Regulación emocional y psicopatología: el modelo de vulnerabilidad/resiliencia. Rev Chil Neuro-Psiquiat, 43-3, 201-209.

Tuvilla Rayo, J. (2004). Cultura de paz, derechos humanos y educación para la ciudadania democrática. Bilbao: Editoria Desclée.

Villanueva, L., Prado Gascó, V., González, R., \& Montoya, I. (2014). Conciencia emocional, estados de ánimo e indicadores de ajuste individual y social en niños de 8-12 años. Anales de Psicología, 30-2,772-780.

Vivas García, M. (2003). La educación emocional: conceptos fundamentales. Sapiens. Revista Universitaria de Investigación, 4-2, 2-34. 